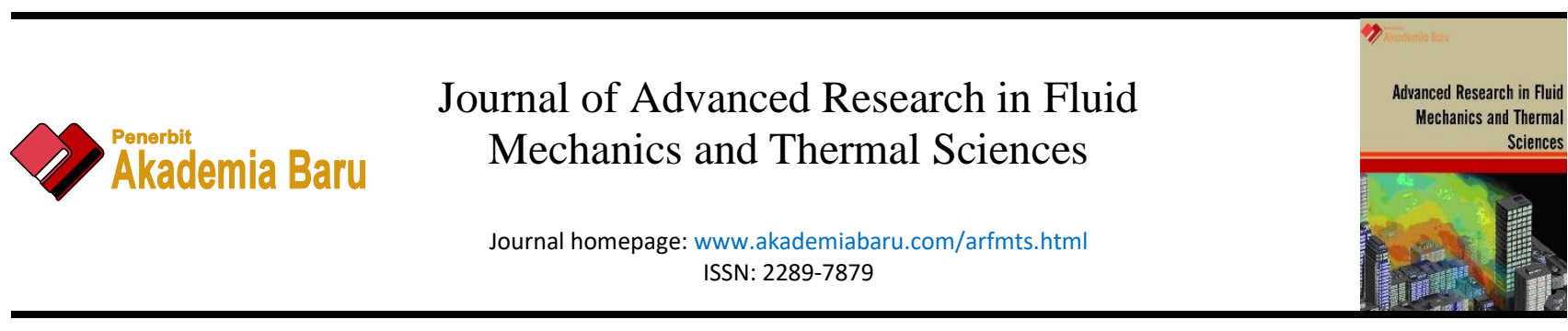

\title{
Combustion Stability Analysis of Liquid Biofuels using Acoustic Signals
}

\author{
Ibrahim Idris Enagi ${ }^{1}$, Khaled Ali Al-attab ${ }^{2,}{ }^{*}$, Zainal Alimuddin Zainal Alauddin ${ }^{2}$ \\ Department of Mechanical Engineering, School of Engineering Technology, Federal Polytechnic, P.M.B 55, Bida, Niger State, Nigeria \\ School of Mechanical Engineering, Engineering Campus, Universiti Sains Malaysia, 14300 Nibong Tebal, Penang, Malaysia
}

\section{ARTICLE INFO}

\section{Article history:}

Received 3 May 2020

Received in revised form 28 August 2020

Accepted 7 September 2020

Available online 9 October 2020

\section{ABSTRACT}

Biodiesel and vegetable oil suffer from higher viscosity and boiling point resulting in poor atomization and evaporation rate compared to diesel fuel additional to the lower heating value which negatively affect the stability of flame. The unsteady heat release rate from flame provides unique pressure wave signature that can be captured as acoustic wave. A pressurized combustion chamber was developed and connected to a vehicular turbocharger to test combustion stability and emissions of wide range of liquid biofuels. Biodiesel and blends of palm oil/diesel from 10\% (Vol.\%) up to $100 \%$ pure palm oil (i.e. P10-P100) were investigated and compared to diesel as the benchmark fuel. Microphone probes at the chamber inlet and outlet were used to capture the acoustic signals to be analyzed through the Fast Fourier Transform (FFT) using MATLAB program. The analysis of the acoustic signals revealed distinguishable deviation patterns between diesel and other biofuels which showed close resemblance to the carbon monoxide (CO) emission patterns at the same operating pressures. Biodiesel was comparable to P20, while increasing palm oil blend resulted in higher deviation. Chamber pressure also showed positive effect on combustion stability and reduced the deviation between diesel and other biofuels.

\section{Keywords:}

Liquid biofuels; Combustion acoustics; Micro gas turbine; Combustion stability

Copyright @ 2020 PENERBIT AKADEMIA BARU - All rights reserved

\section{Introduction}

The sensitivity of gas turbine combustors is limited toward the interaction between acoustic and flame in the combustion chamber (thermo-acoustic). One of the major problems affecting modern high-performing combustion chamber is thermo- acoustic instability, which consists of low frequency pressure and heat release oscillations, couplings, and self-sustenance of large amplitudes [1]. Thus, combustion process can create acoustic waves through volume fluctuations inside the combustor caused by the unsteady heat release. This unsteady heat release often results to temperature fluctuations, which is usually known as entropy waves. The acceleration of these entropy waves at

\footnotetext{
* Corresponding author.

E-mail address: khaled@usm.my
}

https://doi.org/10.37934/arfmts.76.1.145155 
the combustor exit also generates acoustic waves indirectly. The thermos-acoustic instabilities that occurred in many combustion chambers may be a potential threat to the combustion chamber performance and machinery structure. Some of the effects that arises due to combustion instability includes reduction in combustion efficiency, vibrational phenomena, non-uniform exhaust gas thermal distribution, wall thermal stresses and growth of thermal nitrogen oxides (NOx) emissions. The resonant coupling between pressure distribution in the flame region with synchronized heat release rate results in accumulation of acoustic energy around the Eigen modes of the combustor [2]. The sound pressure distribution and determination of acoustic modes are preliminary and necessary steps needed in prediction of combustion stability and identifying their possible locations [2]. Other applications of the acoustic signals include identification and characterization of sound power radiated by engine components and acoustic analysis of reciprocating engines [3-6].

Low-grade liquid biofuels from agricultural wastes are promising renewable alternatives contributing to the wellbeing of the underdeveloped rural areas as well as the reduction in carbon footprint through distributed cogeneration. However, such fuels suffer from the poor atomization and flame fluctuation caused mainly by the high viscosity as well as the low evaporation rate and heating value. The conventional method to determine combustion completion is by analysing the temperature and emission profiles, but it does not provide explicit indication on flame stability. Therefore, new areas of combustion research have been exploited to understand and control combustion oscillations. Many studies have been performed to provide solutions and deeper understanding to combustion instability in combustion chambers using acoustic signals [7-9]. In order to understand combustion oscillations, it is necessary to collect and analyse the acoustic signals produced during combustion process [10]. The contributions of thermo-acoustic phenomena in combustion chamber and entropy noise to flame acoustic interactions are promoted by lean premixed combustion [11,12]. Furthermore, using combustion acoustic interactions in an unstable combustion, a non-existence phase-resolved temperature data was investigated, while heat release fluctuations were examined from swirl combustion using methane, Propane and strong low frequency combustion instability using Jet fuel [7,8,13-15].

All the aforementioned studies investigated the fundamental effect of the elevation in temperature and pressure on acoustic signal generation. This includes the measurement of magnitude, frequency and propagation of localized sound waves inside the different zones of the chamber. However, there still no mature technology to indicate directly the flame stability using acoustic signals. Also, from the practical point of view, collecting acoustic signals from the hot-zones inside the chamber as an analytical tool to diagnose the combustion stability might not be feasible. The current study, on the other hand, proposes the implementation of sound waves in and out of the chamber, where the signals are compared to a reference benchmark signal at the same operating conditions. The development of new analytic tool on MATLAB to compare the flame stability of various fuels to a reference fuel using combustion acoustics captured through microphones was achieved. To achieve this, combustion stability analysis of liquid biofuels using acoustic signal from a pressurized combustion chamber that was developed and connected to a vehicular turbocharger was performed using microphone probes at the inlet and outlet of the combustion chamber. Combustion stability of biodiesel and blends of palm oil/diesel were investigated and compared to diesel as the benchmark fuel. 


\section{Experimental Details}

\subsection{Combustion Chamber Set Up}

The micro gas turbine (MGT) test rig based on Garrett GT25 turbocharger was developed and tested in previous study [16]. Three microphones were provided and connected to the combustion chamber as shown in Figure 1. The microphones are standard 1/4 inch free-field response types calibrated by manufacturer according to the acoustic measurement standard EN 61094-8:2012. Two microphone probes were fixed at the inlet of air manifold supply to the combustion chamber, while the other one was connected at the exit of the chamber for the measurement of sound pressure fluctuations. In order to dampen the resonance and improve frequency response, the cross-section of microphones was kept constant. The three microphones were identified as static-in, dynamic-in and static-out respectively. For the static-in (and-out), the microphone probes were welded directly to the inlet and outlet manifolds of the chamber. However, for the dynamic-in, the probe pipe was inserted to the centre of inlet manifold facing downward. The microphones are $7 \mathrm{~mm}$ in diameter and $8 \mathrm{~mm}$ long with nominal sensitivity of $35 \mathrm{~dB}$. The sound pressure levels measured as amplitude - frequency spectra wave up to $25 \mathrm{kHz}$. Signals were then measured, conditioned and recorded using high-resolution voice recorders.

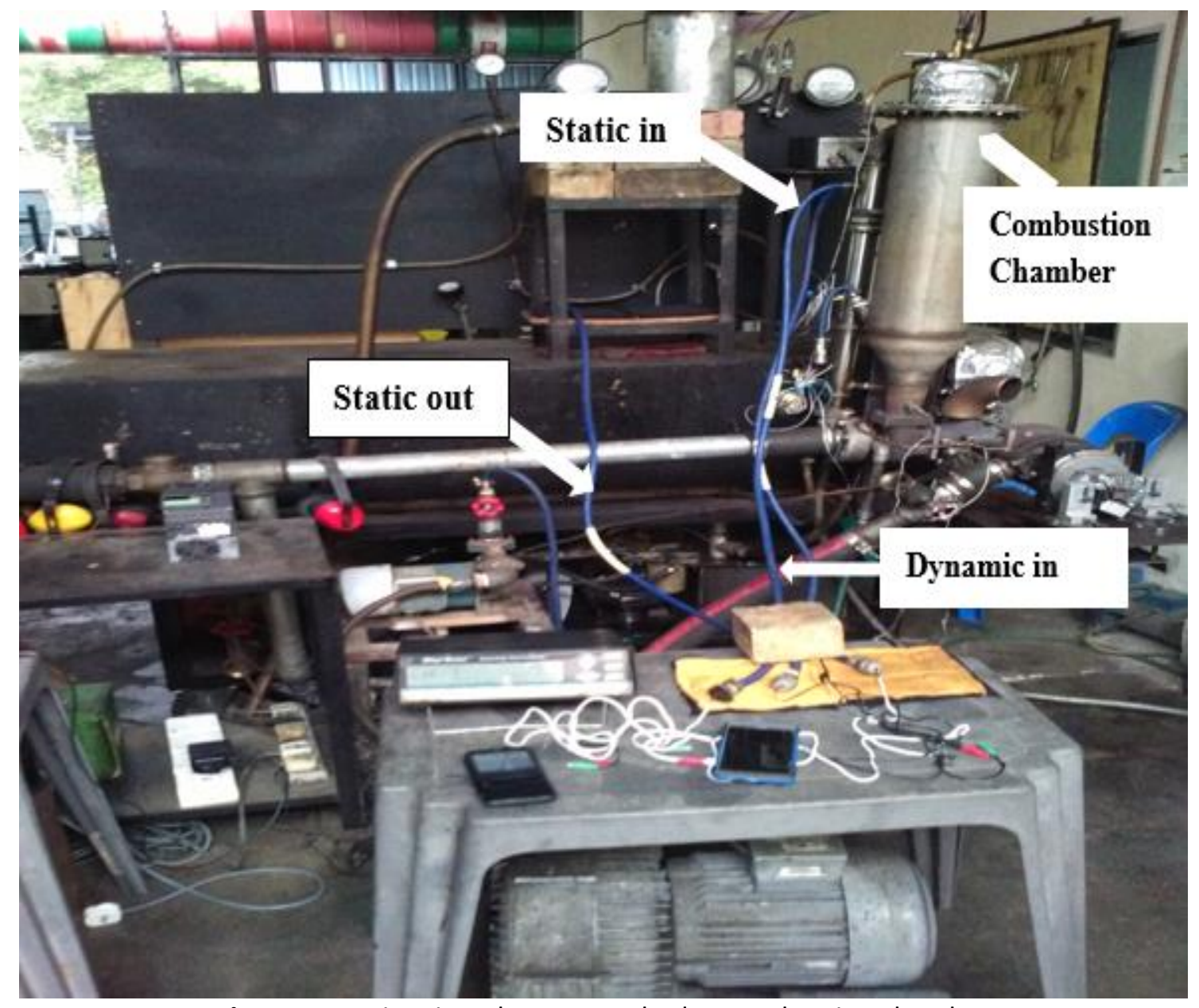

Fig. 1. Acoustic Microphones attached to combustion chamber 


\subsection{Sound Signals Edition}

The sound signal recorded from the combustion chamber was edited by Adobe Audition, a professional tool for precision audio editing, sound mixing and other effects. It is also an industryleading tool for cleaning up recordings and audio restorations. Figure 2 shows a sample waveform in the edit view before editing (a) and after editing (b). The sample graph in Figure 2(a) demonstrates a 17 minutes test run for the MGT where diesel fuel is injected at minute 2 , which resulted in a significant disturbance in the acoustic sound wave. The MGT warmup proses is up to minute 10 followed by setting the fuel setup to the target MGT operating pressure. Finally, the turbine shutdown and cooling at minute 16 . Steady state period is selected in the period (minute 12-13) as shown in Figure 2(b) and the sound clip is cut and saved using Adobe Audition program to be exported to the MATLAB program.
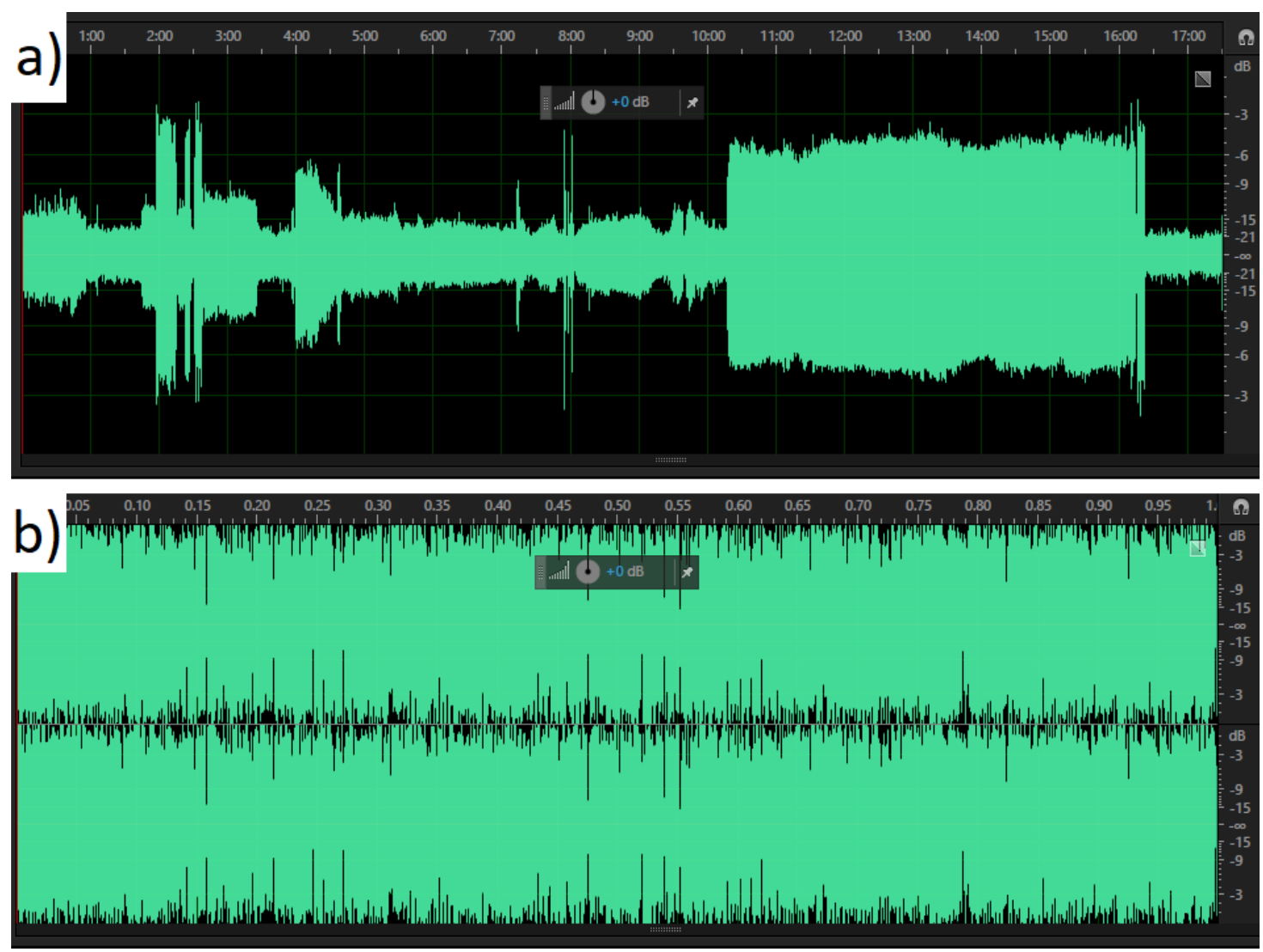

Fig. 2. Waveform of raw acoustic signal (a) before editing and (b) after editing

\subsection{Generation of Frequency Spectrum Plots}

At this stage, MATLAB software is used to convert the acoustic waveform sample that indicates sound amplitude over time into the frequency spectrum form that indicates sound amplitude through the recorded frequency spectrum. Fast Fourier transforms (FFT) algorithm was used to obtain the sound power spectrum. The data obtained were divided in to 100 equally spaced ensembles. These ensembles were then averaged over 100 to obtain power spectra densities (PSDs). Further processing of these ensembles produced averaged spectra with 15 - point ( 15Hz width) moving average. The MATLAB code starts with the selection of the sound wave sample file to determine the sampling rate. Power spectrum is then generated using FFT algorithm. The sound 
power magnitude is then converted into the magnitude of noise in decibel $(\mathrm{dB})$ against frequency $(\mathrm{Hz})$ using Eq. (1).

$d B$ value $=20 \times \log _{10}($ magnitude $)$

The plots of $d B$ are then generated for all the tested fuels. However, it should be noticed that the signal magnitude (or $\mathrm{dB}$ ) is not relevant here, since the absolute $\mathrm{dB}$ values are not used in the fuel stability analysis. The generated $\mathrm{dB}$ values of the different tested liquid biofuels are then divided by diesel benchmark as shown in Eq. (2), and the $\mathrm{dB}$ ratio plots are generated.

$d B$ ratio $=d B$ value for other fuel $/ d B$ vlue for diesel

After that, one standard deviation is calculated for the $\mathrm{dB}$ ratio to approximate the deviation of the tested fuel from the benchmark fuel, and all tested fuels are then compared relative to the same baseline. Exact same values were set for the MGT operating conditions in terms of turbine pressure and flow rate for both fuels in the $\mathrm{dB}$ ratio and the signal was taken for the steady state period as discussed earlier. The MGT shaft frequency is determined from the compressor map of Garrett GT25 at the measured pressure and flow rate. Therefore, frequency range of the mechanical noise from the MGT shaft and bearings up to $4 X$ of the shaft frequency is determined and the $\mathrm{dB}$ ratio values with the expected margin of $0.5<\mathrm{dB}$ ratio $<1.5$ is examined and evaluated.

\section{Results}

\subsection{Power Frequency Spectrum Analysis}

The plots for all liquid biofuels and diesel were generated for pressures of 0.1 to 0.5 bar. The performance of all acoustic signals from all the three reference points (Static in, dynamic in and static out) were clearly shown from the plots. A sample of 0.1 bar plot of $\mathrm{dB}$ against frequency for diesel fuel is shown in Figure 3. It shows that "static out", used as reference point in this work, displayed lower pressure noises of less than $80 \mathrm{~dB}$ due to the pressure drop through the chamber when compared to "static in" and "dynamic in" that showed higher magnitudes of above $80 \mathrm{~dB}$. The general trend is in a good agreement with the finding of other researchers in axial combustor configuration where higher noise is generated at lower frequencies followed by graduate drop in $\mathrm{dB}$ values along the frequency spectrum $[7,8]$. Also, the fluctuation in $d B$ values increase at higher frequencies above $500 \mathrm{~Hz}$ mainly due to the fast pressure oscillation caused by the irregular heat release [9]. 


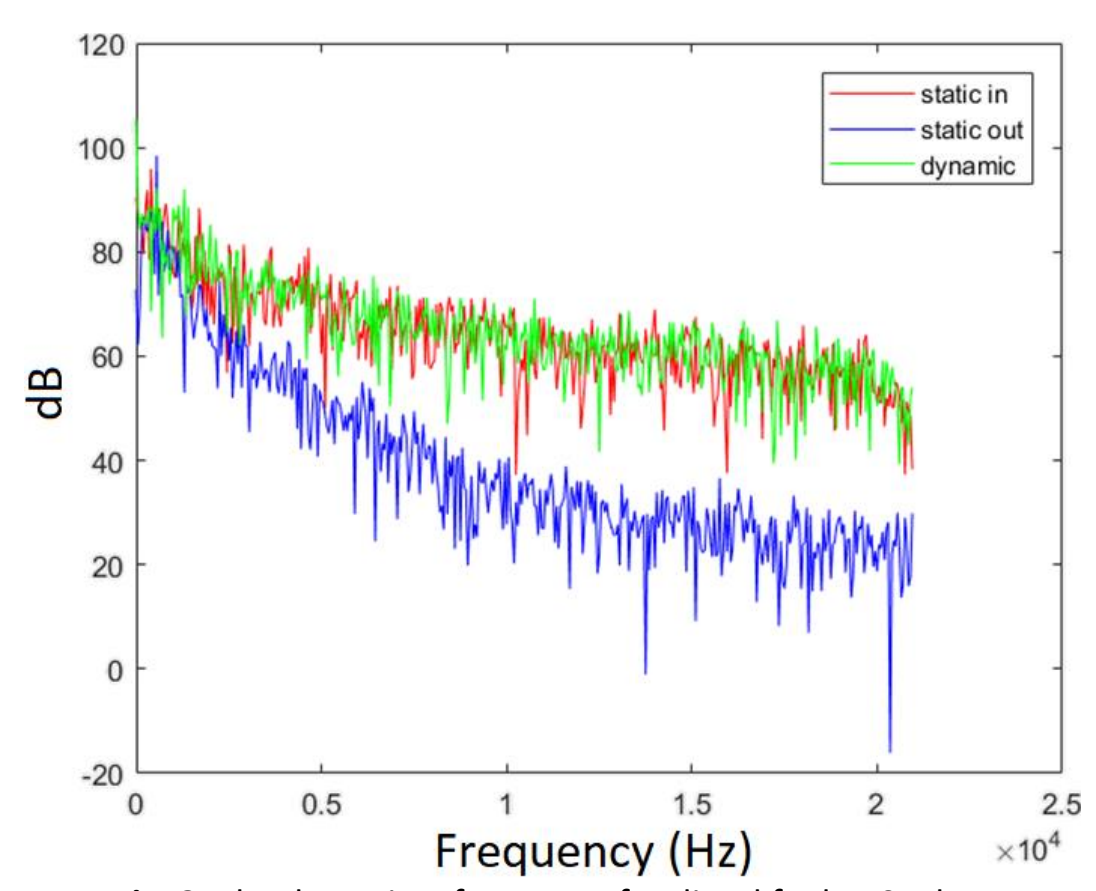

Fig. 3. The $d B$ against frequency for diesel fuel at 0.1 bar

\subsection{The Db Ratio and Normalized Db Ratio Plots}

Using the $d B$ plots for the tested fuel and the benchmark fuel, the values from the plots are divided and the $d B$ ratio plots against respective frequencies are generated by MATLAB. Figure 4 shows a sample result from MATLAB plot of $d B$ ratio at 0.1 bar for biodiesel / diesel and P40/ diesel for static out pressure noise. Biodiesel and $\mathrm{P} 40$ showed similar dB ratio range. However, value spikes higher than a ratio value of 2 can be seen in the graphs even though the raw dB values did not reveal any large difference between diesel and these two fuels. Based on the $\mathrm{dB}$ standard calculation shown earlier in Eq. (1), negative $d B$ values can occur, which can cause these spikes. Therefore, the vertical axis in the plots was normalized by shifting all values to avoid any negative $\mathrm{dB}$ values along the frequency spectrum for $\mathrm{dB}$ ratio calculation.

Figure 5(a) shows a sample of the normalized dB-frequency spectrum derived from the acoustic signals for diesel and biodiesel fuels at 0.1 bar MGT pressure. After that, the normalized Biodiesel/diesel $\mathrm{dB}$ ratio is plotted as shown in Figure $5(\mathrm{~b})$. The turbine speed at 0.1 bar is in the range of $30,000-40,000 \mathrm{rpm}$ which correspond to frequency range of $0.5-0.67 \mathrm{kHz}$, which resulted in the peak noise level seen in the plots. Most of the mechanical noises from the normal shaft speed (i.e. $1 X$ ) up to $4 \mathrm{X}$ for the bearing noise which is still below $3 \mathrm{kHz}$ were cancelled in the dB ratio plot, resulting in low noise ratio margin of $(0.8-1.2)$ which is not expected to have any effect on the deviation values. 


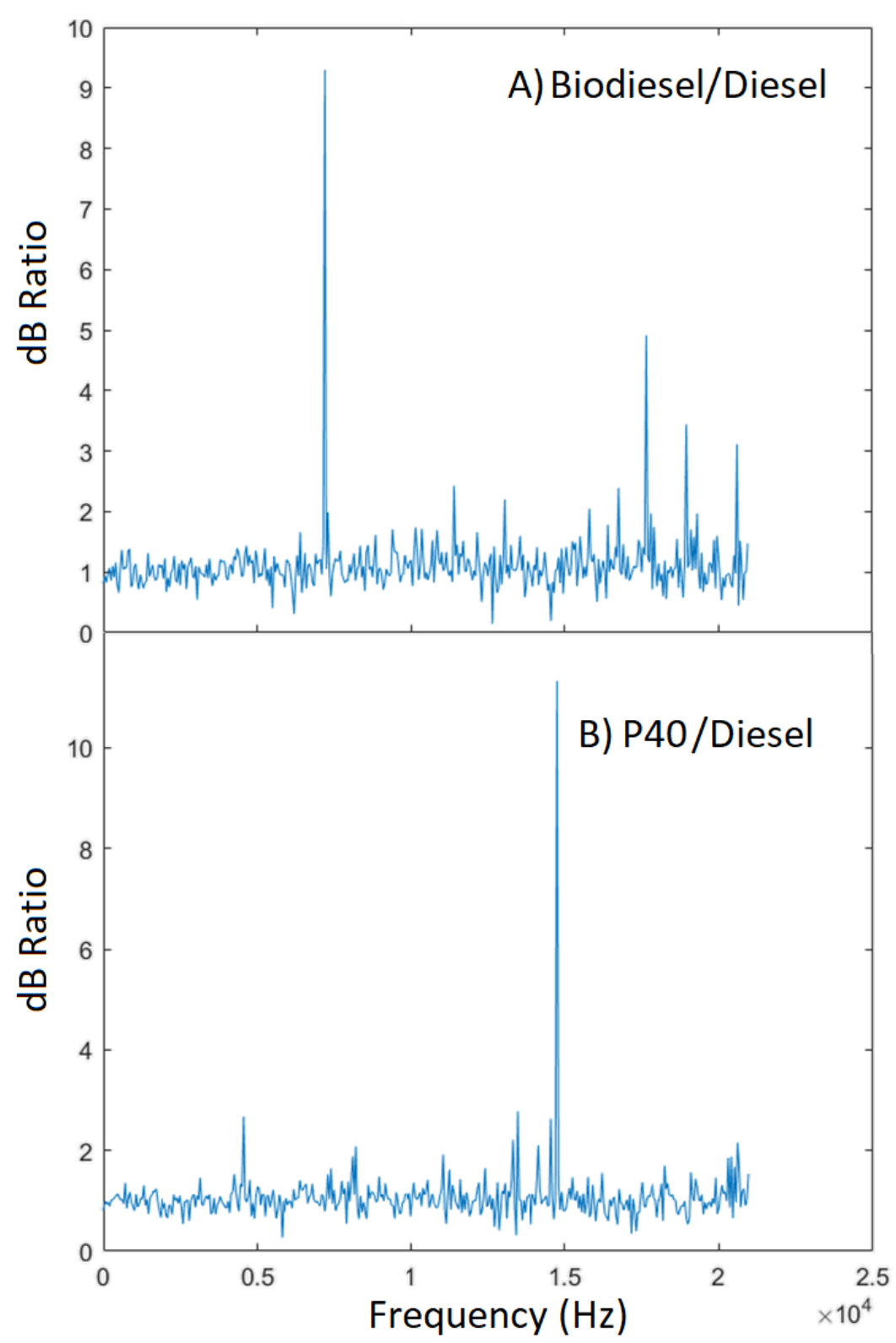

Fig. 4. The $d B$ ratio at 0.1 bar for (A) diesel/ biodiesel; (B) diesel/P40 


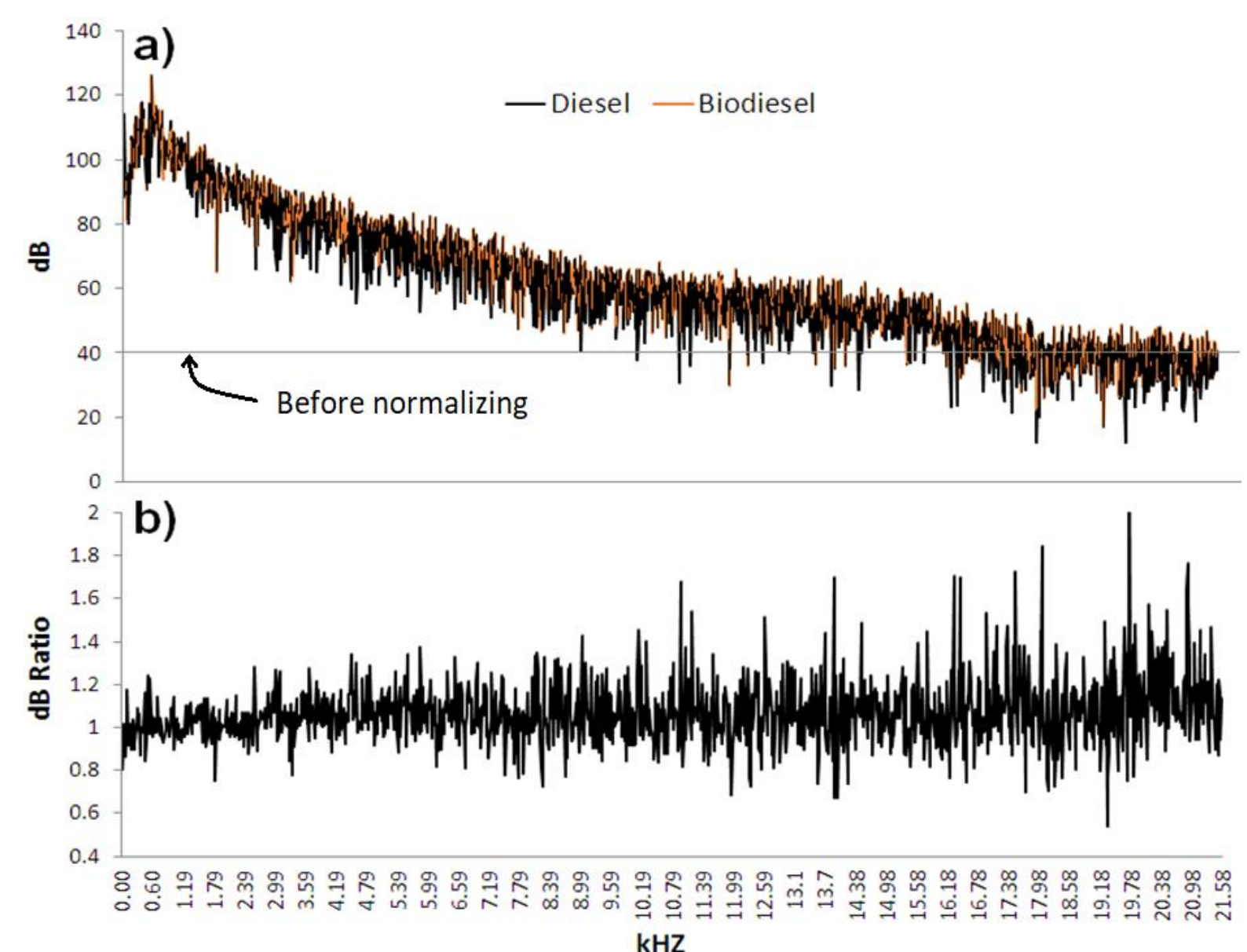

Fig. 5. (a) dB-frequency spectrum derived from the acoustic signals for diesel and Biodiesel fuels at 0.1 MGT pressure and (b) biodiesel/diesel dB ratio

\subsection{Noise Deviation and MGT Stability Analysis}

Average Standard deviation value is calculated from the $d B$ ratio plots for each fuel which indicates the deviation of the different fuels from the reference diesel fuel in terms of the acoustic noise generation. Pressure oscillation can be caused by the flame oscillation and irregular heat release due to the sudden changes in flame location which can be captured by acoustic signals [14]. All the tested biofuels suffer from the high viscosity and boiling point which results in poor fuel atomization and evaporation. This issue is more prominent at low MGT operating pressure where combustion temperature is low resulting in lower combustion quality and higher flame fluctuations compared to diesel fuel. This was clearly indicated by the high deviation from diesel for the majority of the tested fuels at lower operating pressure conditions as shown in Figure 6(a). Pure palm oil (i.e. P100) suffered the most and the combustion was not stable in the pressure range of 0.1-0.3 bar with frequent flame blow-off. Thus, steady-state operation and stable acoustic recordings were available only for pressures of 0.4 and 0.5 bar. The deviation from diesel started gradually from P20 to P60 with consistent patterns. However, P80 showed inconsistent deviation levels at the different operating pressure levels with maximum deviation at 0.4 bar. As for biodiesel, the deviation values were between P20 and P40, which is in a good agreement with combustion performance characteristics in terms of carbon monoxide (CO) emissions shown in Figure 6(b). The patterns generated from the deviation values at different MGT operating pressures were in good agreement with the patterns of $\mathrm{CO}$ emissions for the tested biofuels. In general, operating at higher pressure 0.5 
bar resulted in low deviation and $\mathrm{CO}$ emission values indicating good flame stability, which is comparable to diesel fuel combustion.

The general trend showed that the improvement in combustion stability when increasing MGT pressure was more pronounced when the fuel is of a lower quality when measured by noise deviation as well as $\mathrm{CO}$ emission. The total reduction in deviation was $12 \%$ for P40 and $18 \%$ for P60 through the full pressure range. For P80, the largest deviation was $20 \%$, but the results did not follow a consistent pattern. As for $\mathrm{P} 100$, only two readings were available with a reduction of $6 \%$, but when extrapolating the data, the reduction can go up to $20 \%$. At 0.5 bar, all the tested fuels showed low deviation from diesel with only $10 \%$ difference between the fuels. $\mathrm{CO}$ emission data followed similar trend but with different emission reduction scale from 19\% for P20 up to 51\% for P80.

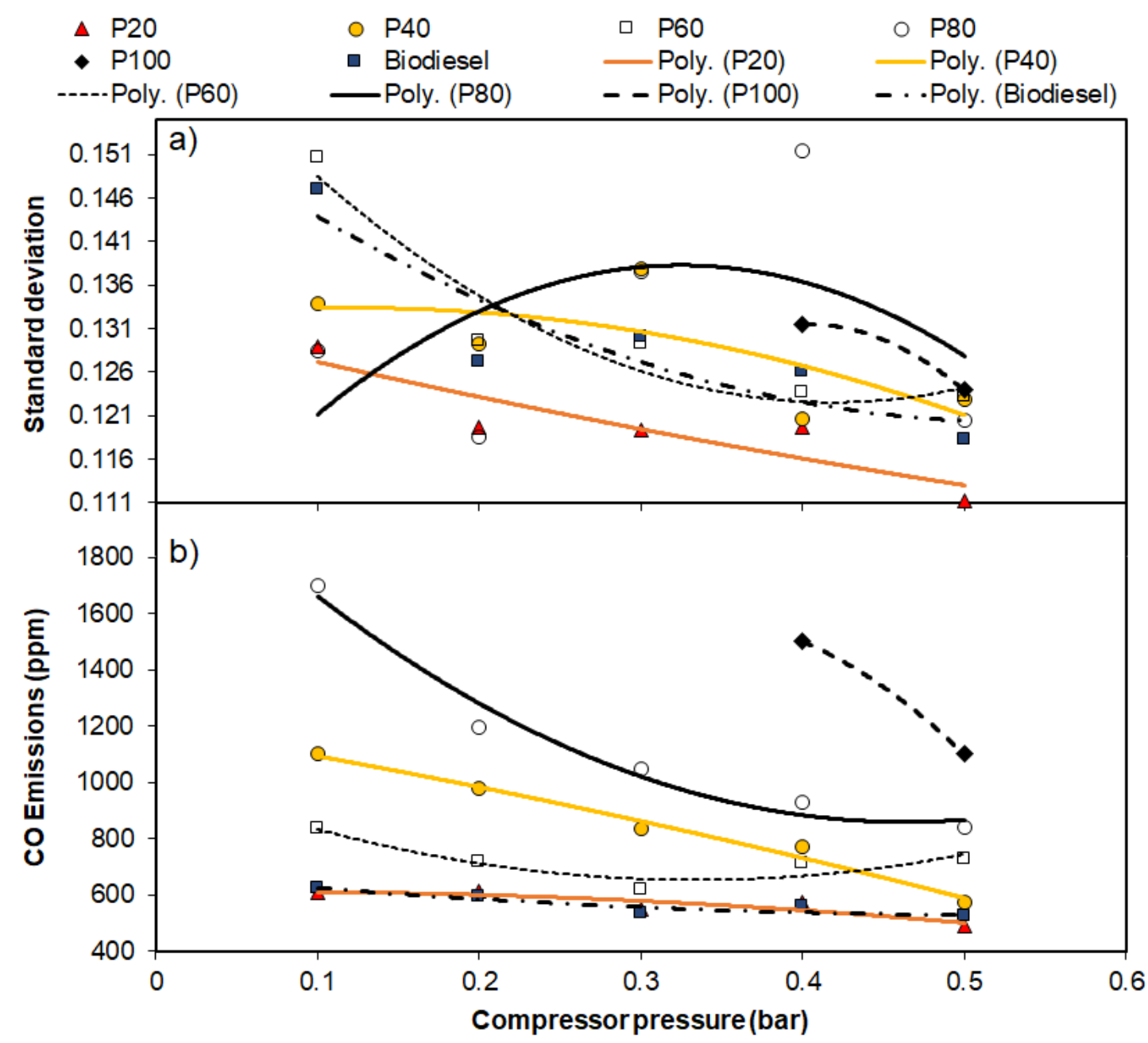

Fig. 6. (a) Sound level deviation from dB ratio of 1 for biofuels with diesel as a reference fuel; (b) MGT CO emissions for biofuels

\section{Conclusions}

Combustion stability of the MGT combustion chamber was characterized for wide range of biofuels including biodiesel, palm oil/diesel blends and pure palm oil using the flame acoustic analysis and CO emissions. A new analytical tool developed on MATLAB program using combustion acoustic signals as the input was used to compare the flame stability of biofuels to the reference fuel, which is diesel in the current investigation. Acoustic flame stability analysis showed distinguishable differences between the fuels with noticeable variation in physical properties, compared to diesel, 
such as higher blends P60 to P100 and biodiesel. Most of the tested biofuels suffered at the lower operating pressures due to the low combustion temperature resulting in poor atomization which improved significantly at higher pressures up to 0.5 bar. This was clearly reflected on the acoustic deviation charts as well as the $\mathrm{CO}$ emission values which can be taken as preliminary measurement for combustion quality. The acoustic deviation patterns were in a good agreement with $\mathrm{CO}$ emission patterns throughout the MGT pressure range of 01.-0.5 bar.

\section{Acknowledgement}

The authors would like to thank the Ministry of Education Malaysia, Fundamental Research Grant Scheme (FRGS) No.: 203.PMEKANIK.6071426 for the financial support of this study.

\section{References}

[1] Fichera, A., C. Losenno, and A. Pagano. "Experimental analysis of thermo-acoustic combustion instability." Applied Energy 70, no. 2 (2001): 179-191. https://doi.org/10.1016/S0306-2619(01)00020-4

[2] Richecoeur, Franck, Thierry Schuller, Ammar Lamraoui, and Sébastien Ducruix. "Analytical and experimental investigations of gas turbine model combustor acoustics operated at atmospheric pressure." Comptes Rendus Mécanique 341, no. 1-2 (2013): 141-151.

https://doi.org/10.1016/i.crme.2012.11.008

[3] Paillasseur, Sébastien, and Claire Chaufour. "Measurement of component's sound power emission on a PSA's diesel engine by means of 3D acoustic imaging techniques, and its applications." In Congrès Français de Mécanique. AFM, Association Française de Mécanique, 2015.

[4] Siano, D., and M. A. Panza. "Sound quality analysis of the powertrain booming noise in a Diesel passenger car." Energy Procedia 126 (2017): 971-978. https://doi.org/10.1016/i.egypro.2017.08.189

[5] Chiatti, Giancarlo, Ornella Chiavola, and Fulvio Palmieri. "Vibration and acoustic characteristics of a city-car engine fueled with biodiesel blends." Applied Energy 185 (2017): 664-670.

https://doi.org/10.1016/i.apenergy.2016.10.119

[6] Armentani, Enrico, Raffaele Sepe, Antonio Parente, and Mauro Pirelli. "Vibro-acoustic numerical analysis for the chain cover of a car engine." Applied Sciences 7, no. 6 (2017): 610. https://doi.org/10.3390/app7060610

[7] Singh, A. V., A. Eshaghi, M. Yu, A. K. Gupta, and K. M. Bryden. "Simultaneous time-resolved fluctuating temperature and acoustic pressure field measurements in a premixed swirl flame." Applied Energy 115 (2014): 116-127. https://doi.org/10.1016/j.apenergy.2013.10.058

[8] Singh, A. V., M. Yu, A. K. Gupta, and K. M. Bryden. "Investigation of noise radiation from a swirl stabilized diffusion flame with an array of microphones." Applied Energy 112 (2013): 313-324. https://doi.org/10.1016/i.apenergy.2013.06.034

[9] Ruan, Can, Feier Chen, Tao Yu, Weiwei Cai, Xinling Li, and Xingcai Lu. "Experimental study on flame/flow dynamics in a multi-nozzle gas turbine model combustor under thermo-acoustically unstable condition with different swirler configurations." Aerospace Science and Technology 98 (2020): 105692. https://doi.org/10.1016/j.ast.2020.105692

[10] Farhat, Salem A., and Mohamed K. Al-Taleb. "Combustion oscillations diagnostics in a gas turbine using an acoustic emissions." Jordan Journal of Mechanical and Industrial Engineering 4 (2010): 352-357.

[11] Wassmer, Dominik, Bruno Schuermans, Christian Oliver Paschereit, and Jonas P. Moeck. "An Acoustic Time-of-Flight Approach for Unsteady Temperature Measurements: Characterization of Entropy Waves in a Model Gas Turbine Combustor." Journal of Engineering for Gas Turbines and Power 139, no. 4 (2016). https://doi.org/10.1115/1.4034542

[12] Bake, Friedrich, Ulf Michel, Ingo Röhle, Christoph Richter, Frank Thiele, Martin Liu, and Berthold Noll. "Indirect combustion noise generation in gas turbines." In 11th AIAA/CEAS Aeroacoustics Conference, p. 2830. 2005. https://doi.org/10.2514/6.2005-2830

[13] Lee, Jong Ho, Chung Hwan Jeon, Young June Chang, Chul Woong Park, and Jae Won Hahn. "Experimental study on flame structure and temperature characteristics in a lean premixed model gas turbine combustor." Journal of Mechanical Science and Technology 19, no. 6 (2005): 1366-1377.

https://doi.org/10.1007/BF02984057 
[14] Khalil, Ahmed EE, and Ashwani K. Gupta. "Acoustic and heat release signatures for swirl assisted distributed combustion." Applied Energy 193 (2017): 125-138. https://doi.org/10.1016/j.apenergy.2017.02.030

[15] Temme, Jacob, Patton Allison, and James Driscoll. "Low frequency combustion instabilities imaged in a gas turbine combustor flame tube." In 50th AIAA Aerospace Sciences Meeting including the New Horizons Forum and Aerospace Exposition, p. 542. 2012. https://doi.org/10.2514/6.2012-542

[16] Enagi, Ibrahim I., Khaled A. Al-attab, and Zainal Alimuddin Zainal. "Liquid fuels spray and combustion characteristics in a new micro gas turbine combustion chamber design." International Journal of Energy Research 43, no. 8 (2019): 3365-3380.

https://doi.org/10.1002/er.4475 